\title{
Affirmative Action as a Strategy for Promoting Women's Participation in Politics in the Frafra Traditional Area of Ghana
}

\author{
Francis Issahaku Malongza Bukari \\ Department of Environment and Resource Studies, \\ University for Development Studies, Wa Campus, Ghana \\ malongza@outlook.com
}

Agnes Atia Apusigah

Faculty of Education, University for Development Studies, Tamale, Ghana

\section{Cynthia Itboh Abagre}

Institute for Continuing Education and Interdisciplinary Research, University for Development Studies, Tamale, Ghana

DOI//http://dx.doi.org/10.4314/gjds.v14i2.7

\begin{abstract}
While the use of affirmative action to increase women's political participation in societies where socio-cultural factors militate against women's political interests, popular measures do not go beyond quota systems. This paper therefore examines the ideological, programmatic and socio-cultural impacts of affirmative action on women's political participation in the Frafra traditional area of Ghana, using a qualitative research approach. Results indicated that ideologically, affirmative action is perceived as policies and strategies that aim at the protection of the interests of women's interest in politics. Programmatically affirmative action programmes such as capacity building and mentoring of women for participation in political leadership were found to be based on existing policies. Socio-cultural factors were found to be a major impediment to affirmative action programmes for the promotion of women's political participation. Hence, it was concluded that the use of affirmative action for the promotion of women's political inclusion would remain ineffective unless the socio-cultural factors that undermine them are addressed.
\end{abstract}

Keywords: Affirmative Action, Women's Political Inclusion, Frafra Traditional Area 


\section{Introduction}

Gender issues are of concern in development and are often incorporated into national development plans and international treaties such as the Beijing Platform for Action (1995), the Millennium Development Goals (Bukari, 20o9) and the Sustainable Development Goals. However, a major challenge is the apparent contrast between modern advocacy for gender equity, and socio-cultural antecedents that offer women no better place than the kitchen (Apusigah, 2004). For instance, of the 45,113 parliamentarians in the world in 2015, women constituted only $22.5 \%$ compared to $77.5 \%$ of men, with Nordic countries having $41.1 \%$ as the highest representation of women (Regional Parliamentary Assemblies, 2015).

In Africa, women occupied 23\% of parliamentary seats in 2015 (Regional Parliamentary Assemblies, 2015), while in Ghana, of the 133 women who contested in the 2012 parliamentary elections, only $28.8 \%$ won, who constituted only $10.5 \%$ of the 275 total parliamentary seats (Akpah, 2013; Ghana News Agency, 2013). These fall short of International Union of Local Authorities' (IULA) provision, that no gender group should have less than 40 percent or more than 60 percent representation in local level political positions (Ballington, 2004).

Political representations at the national, regional and local levels remain skewed in favour of men in Ghana. Civil societies, women's rights organisations, donor partners and government agencies such as the Department of Women (DoW) of the Ministry of Gender, Children and Social Protection, have evolved strategies to enhance women's participation in politics for many years without substantive results (Abagre, 2012).

The Frafra traditional area, comprising the Bolgatanga Municipality, Talensi, Nabdam, Bongo and Tongo Districts of the Upper East Region of Ghana is one of the patriarchal societies in the country, with elderly males being the family and clan heads. Apusigah (2004), reports that even in matters that concern the lives of women in a family, they get to know of it only when the elders have already concluded. The system of inheritance is also patrilineal, in which only males inherit family property such as land. The woman's place is the kitchen, child bearing and upbringing, caring for the sick and aged, and extending hospitality to strangers who visit the family and other reproductive roles (Zuul, 2011). This social orientation at the family level has been so effective that even fellow women would scold a woman who appears to be too vocal at community meetings where major decisions are made with both men and women present (Apusigah, 2004). This situation tends to affect women's motivation to participate in community and national level politics (Bari, 2005). 
One of the ways of addressing gender inequality in politics is by affirmative action (AA). AA is a social construct of institutional consciousness and proactive remedial responses aimed at tackling vulnerability, exclusion, marginalisation and discrimination in order to eliminate inequalities in access to justice. According to Women in Law and Development in Africa (WILDAF, 2010: 5), "affirmative action policy is a deliberate attempt at reforming or eliminating past and present discrimination using a set of public policies and initiatives designed to help on the basis of colour, creed, geographical location, race, origin, and gender, among others". In practice, the varied nature of the plight of vulnerable groups requiring affirmative action often draws in a spectrum of development actors from the private sector, international organisations and relevant public sector institutions as well.

Tsikata (2009), also considers affirmative action as a mechanism that seeks to improve development indicators by reducing inequalities and facilitating the contribution of particular social groups to development, and so relates to both the distributive and productive aspects of development. We could therefore, explain affirmative action contextually to mean a concept encapsulating principles, strategies, plans, programmes, projects and activities aimed at achieving set goals and objectives, which are measurable and verifiable, through observable indicators of change in the object of women's vulnerability to unequal access to political participation, in a defined socio-cultural and geographical context.

Empirically, Meena (2004) reports that the adoption of the quota system of allocating a specific number of parliamentary seats to women irrespective of franchise results was to enhance women's participation, since socio-cultural factors would always militate against them. Affirmative action, however, lacks democracy since women appointed by such procedure do not represent the people's interests. Tamale (2004) also posits that despite the introduction of the quota system in Uganda, the system fails to ensure equity in political participation by gender. This was because the number of seats reserved for women was not based on proportions. At the same time women appointed by such a mechanism were limited to roles related to women's issues, such as 'Secretary for Women'.

In Ghana, the Local Government Act and National Gender and Children's Policy are important documents on affirmative action, with the 1998 Affirmative Action Framework being the most comprehensive. However, the lack of implementation has been cited for the lack of progress. While socio-cultural factors are continually impinging on AA initiatives, there has not been any concerted effort to examine the nature and extent of AA as a tool for deriving the socio-cultural changes that are needed in the Frafra traditional area and the country at large. Such an undertaking is important for determining the programmatic suitability and contextual appropriateness of AA as a 
tool for social change. The study therefore sought to address the identified gap by finding answers to the main research question, stated as: "How does affirmative action as a strategy promote women's participation in politics in the Frafra traditional area?"

\section{Conceptual Overview}

The Social Transformation Framework (STF) provided the structural guide for this study. This explains the combined effects of psycho-social and transformational strategies in causing social change. It illustrates how an undesirable aspect of an individual's life transits to what is desirable through changes in the social system (Kaufman, 2003). Where a transformation process relates to aspects of the culture of a people, it is described as a social transformation through collective consciousness (Stone \& Gregory, 1957; Kubilay, 2008). The STF has three basic elements: vulnerability context, psychosocial domains and transformational processes (Gauthamadas, 2005). Figure 1 starts with the identification of a particular event. Thus, a social transformation is defined if the social event providing the basis for diagnosing and conceptualising the elements of transformation is known. For example the exclusion of women from political participation is an event.

The vulnerability, psycho-social and transformative elements are then examined from this event. The vulnerability context refers to the adverse consequences that a social unit may be exposed to, due to the influence of external forces, but could also be remedied by interventions from external supports (Department for International Development (DFID), 2008; Scoones, 1998). Contextually, True, George, Niner and Parashar (2014) observe that the vulnerability of women to exclusion from political participation is a global problem. For instance, women occupied only $22.5 \%$ of parliamentary seats in the world in 2015 (Regional Parliamentary Assemblies' (2015).

The psycho-social domain relates to existing socio-cultural factors that perpetuate the socio-political rhetoric contributing to the vulnerability of a group to an undesirable event. This comprises three sub components: the cultural value, the social ecology and the human capacity, which are interrelated (Mak, 2004).The socio-cultural factors that militate against women's political participation constitute the cultural value. In some societies, socio-cultural factors have de jure or de facto effects on women's participation (True et al., 2008). For instance in patriarchal societies, the exclusion of women from politics tends to be de jure (permanent). Where the society concerned easily adapts to cultural change, this tends to have a de facto (temporary) effect and makes room for women's progress in political participation.

Social ecology refers to the external factors influencing the functioning of the internal socio-cultural values determining the level of women's political inclusion (Mak, 2004: Gauthamadas, 2005). This is followed by human capacity at the local, national and 
global levels to change the dynamics of social eco-systems in the best interest of groups vulnerable to the negative effects of socio-cultural factors (Folke, 2006: UNESCO, 2012). The Convention on the Elimination of all forms of Discrimination against Women (CEDAW), the UN Charter on Human Rights, the Millennium Development Goals (MDGs), and the Sustainable Development Goals (SDGs) are some of the international policy frameworks, offered by social ecology to address women's vulnerability to political exclusion. CEDAW encourages the adoption of measures that promote women's participation in politics, while the UN Charter identifies the role of cultural diversity in introducing positive changes in favour of a vulnerable group, despite the respect for the culture of a people as a human right. The MDGs and SDGs also advocate for gender equality and empowerment of women.

The fundamental bases of these are often incorporated into regional, national and district level development plans and policy frameworks, and institutionally implemented by the appropriate government ministries and departments, local government authorities and civil society organisations. These serve as the institutional machinery that drives the agenda for social transformation (African Union [AU], 2012).

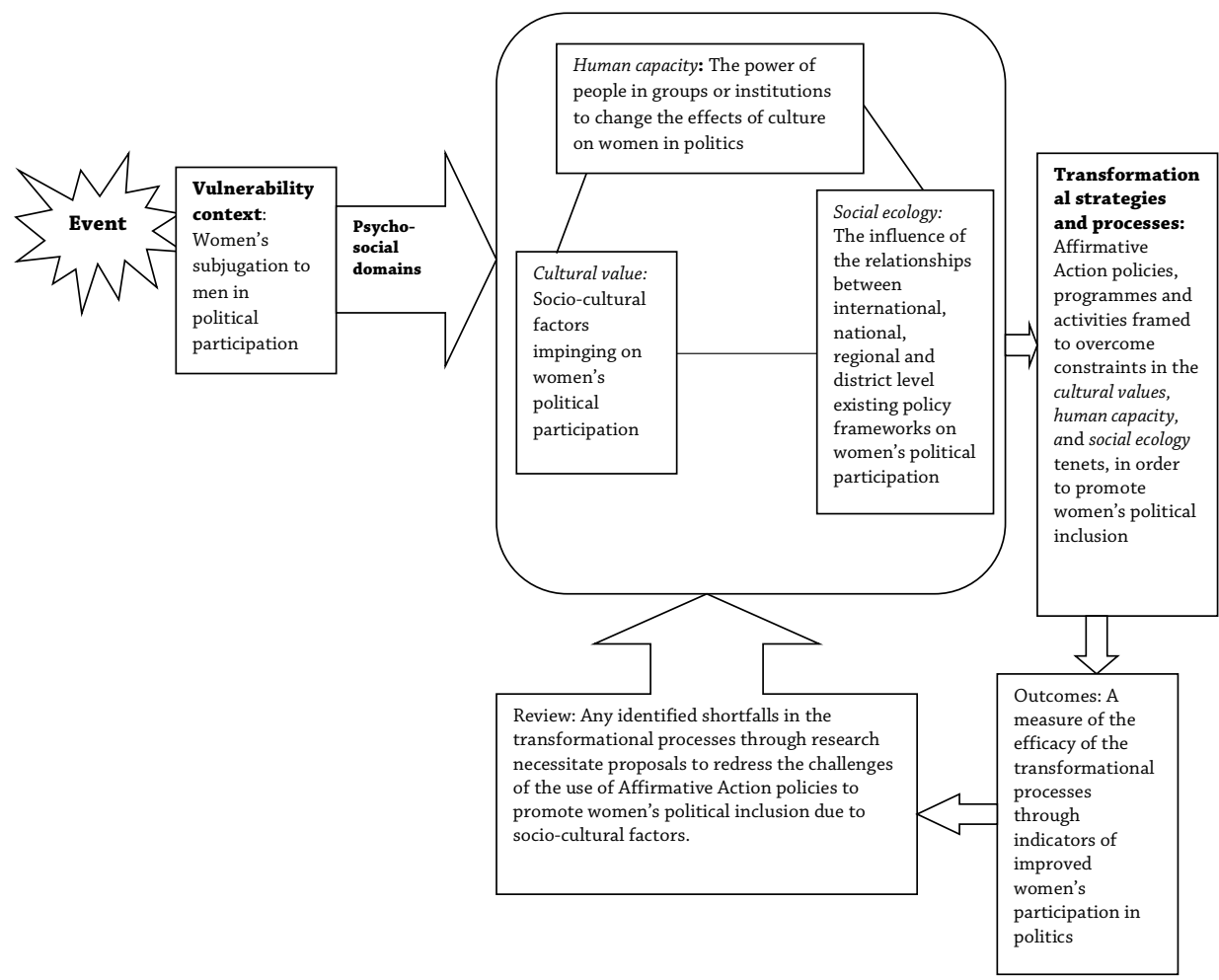

Figure 1: The Social transformation framework

Source: Adopted and modified Mak (2004) as in Gauthamadas (2005: 6) 
The ability of social ecology and human capacity to address the vulnerability of women to political marginalisation depends on how well the socio-cultural antecedents are integrated into the planning and implementation of the social transformation process. Any identified shortcomings imply the need to revisit the component of cultural value, thus repeating a cyclical process in the entire facet of the psycho-social domain. If outcomes of the psycho-social domain are satisfactory, there would be a move towards social change through affirmative action policies, programmes, projects and activities. These would be based on institutional frameworks related to social ecology and the human capacity for the achievement of the anticipated social change (Mak, 2004; Gauthamadas, 2005), such as improved participation of women in politics as the outcome.

The STF is however, limited by the failure to identify shortfalls in the adopted transformation process and how these could be reviewed. The authors therefore considered it necessary for a review of the results of outcomes to inform future interventions for women's political participation through affirmative action.

\section{Methodology}

The study area is the Frafra Traditional Area of the Upper East Region of Ghana. Focus was on three purposively selected local government areas: Bolgatanga Municipality, Talensi and Bongo Districts. Yikene, Sekot and Gowrie communities were chosen by lottery method for Bolgatanga Municipality, Talensi and Bongo Districts respectively.

The study depended on a qualitative research approach. Thus, focus group discussion guide, key informant interview guides and life history interview guides were the main data collection tools. The technique was by face-to-face interview, and responses were transcribed into jotters. The information obtained facilitated detailed verbal explanations and narration of the thematic or empirical issues of this study.

Being a qualitative research approach, a sample size of 100 respondents was nonstatistically selected from the sample frame of selected districts. This falls within the range of 50-100 and above, which is the level at which bias could be avoided and normality of research results assured (Branner, 2007). The sample size included 30 women in politics, 30 male Chiefs and Elders, 30 Women Leaders and Elders, 3 Gender Desk Officers, 3 District Coordinating Directors and 12 officials of NGOs in the area of women's development issues. These were purposively selected. The subject matter of this study being focused on women necessitated the need to have more women on the sample. Results were based on themes related to the research question and shaped by the conceptual framework. Primary data analysis was qualitative, supported by relevant literature. 


\section{Results and Discussion}

The ensuing sections focus on the discussion of the findings of the study based on the research questions and shaped by the conceptual framework.

\section{Socio-Cultural Factors Affecting Women's Political Inclusion in the Frafra Traditional Area}

\section{Cultural Factors Associated with Marriage and their Effects on Women's Political Participation}

Respondents recognised that the cultural factors that limit women's political participation begin from the household level. In a FGD with the Chief and Elders of Yekene an elder said that "a woman is supposed to take up household chores. How then, could she occupy a position outside the home?". This means a woman should have no other responsibilities outside the home (Apusigah, 2004). If she does, such must be related to the keeping of the home, such as gathering water and firewood, helping the husband on the farm and going to the market among others.

At the Yekene, Gowrie and Sakote communities, the life histories, interviews with women presently and formally in politics, and FGD with women, had similar responses. The women raised concerns about certain traditional customs which militate against their rights and freedom to participate in other activities that could improve their living standards, such as expensive bridal price, widowhood rites, inheritance, taboos and other conditions of the patriarchal system.

Common responses obtained from the women FGD participants across the study communities were that, after paying the expensive bridal prices, men often feel they have absolute control over the lives of their wives. They shared the view that once a woman marries, she can hardly take any independent decision for her self-development. A participant at Yekene noted:

It is common for educated women to be denied their rights to further education because a man would not tolerate an empty house without a woman he has already spent so much on. Competent educated women may also be denied the right to participate in party politics. Women who refuse to take such orders are threatened with divorce by their husbands, who could also claim compensations from their wives' families.

Participants at Gowrie, observed that during widowhood rites, a woman is confined for 30 days and is not involved in issues related to inheritance of her late husband's property. Some customs also taboo women from voluntarily participating in decision making during community meetings, unless the male heads draw them in to enable them arrive 
at a resolution that determine the fate of such women. All these affect women's ability to develop the confidence to participate in modern politics.

Most of the traditional notions of the place of men and women in terms of leadership are not only found in the Upper East Region of Ghana but appear to be universal. For instance UNDSEA (2000), cited in Abagre (2012: 40) noted:

In our so called culture, a woman's place is the kitchen. A woman has to support the husband all the time. Once a woman starts to be an effective leader, she will be labelled a prostitute (Ncuba, Zimbabwe). Even the few women that are educated find it difficult to join politics due to the fact that most men will not allow their wives to join politics. Women in politics are considered to be free or loose (Pricilla, Nigeria).

At Gowrie, the women participants were able to identify some good effects of culture on gender and politics. The views were summarised in the contribution of the Mangazia (Women's Leader) of Gowrie as follows:

The ideal woman in the cultural context is one who is capable of winning the favours of her family, husband and the society at large, to the extent that they see all that she does as being good. The culture of the home is therefore the preparatory ground for the outside.

However, socio-cultural factors affecting women's political participation are not only limited to marriage or the household level, but transcend to community level politics.

\section{Socio-cultural Factors at the Community Level Affecting Women's Participation in Politics}

Some socio-cultural factors at the community level were found to be negatively or positively affecting the participation of women in politics. For instance, in a FGD with the Chief and Elders of Yekene, an elder said:

In the tradition of the Frafra, the concept of leadership is embodied in the chieftaincy institution, but chieftaincy is mainly for men. It is in the myth of our tradition that women were already enskinned from heaven, therefore chieftaincy or leadership on earth is reserved for men, women cannot be leaders in heaven and on earth at the same time.

Another participant at Gowrie detailed his conception as follows:

Traditionally, it is a man who can be a chief. Our ancestors established this arrangement after the consideration of some factors, which are still obvious 
today. Chieftaincy is about bravery. It involves the capacity to rule both men and women with high senses of initiative and the adjudication of justice without fear. The added fact that the chief of our community is the commander in chief of the traditional army means that the institution is war-like. During the periods of ethnic wars before organised leadership beyond the male family and clan heads were thought of, women naturally remained indoors with children. When they participated, they merely provided support to the men in the form of the supply of food and water. Women are therefore not recognised in the traditional setting to be capable of taking up leadership positions, but to support men to do so better.

These responses reveal the evolution of the concept of leadership, which is a component of the people's culture. Thus, as boys and girls grow, they identify their roles through socialisation as leaders and caretakers respectively, which they imbibe without question.

The views of women presently and formerly in politics on socio-cultural factors militating against their political and decision making interests, as summarised from the focus group discussions in Yekene, Gowrie and Sakote communities indicated that women are not allowed to have a say in the presence of men; discriminated against with the notion that a woman cannot rule men or be a leader in the locality; and that men always look down upon women and are not prepared to involve them in decision making. Such perceptions about gender originated from the era of traditional fatalistic societies, whose major concerns were about food, shelter and protection from raiders (Bekye, 1998). Women therefore saw no value in fighting for the elimination of these elements of marginalisation.

Today, opportunities for educational and professional development of women on equal basis with men, and the emergence of modern political and administrative systems, as well as the activities of human rights activists, are responsible for the consciousness and need for a change of the obnoxious traditional order, so as to enhance women's contribution to decision making and leadership for development (Tsikata, 2009).

There were also some good effects of socio-cultural factors identified at the community level. The discussion with the Chief and Elders in the three study communities revealed their awareness that culture is subject to change (See Getis, Getis and Fellmann, 2006), but for the change process to be acceptable it must be by the people. An elder at Gowrie said:

If a woman is of us, and has the potentials to work for our common good, we see no reason to keep her back from working for our wellbeing. This is why some women have become successful politicians in the Frafra traditional area. A woman can simply not run away from culture to politics, because, it 
is culture that will determine the political worth of a woman, since even governance by modern politics is by the people.

It also became necessary to explore for evidences on how these factors actually affect women in the Frafra traditional area.

\section{Vulnerability of Women to Inequalities in Leadership and Decision Making}

The study revealed several instances of discrimination in political participation on the basis of gender, and women were seen to be the most vulnerable. A former female Member of Parliament in Yekene-Bolgatanga revealed how she was exposed to discrimination during her political career. This often took the forms of not disclosing the right time of opening nominations to her; nominating only men for district and national level elections with the negative perceptions that women are incompetent for such posts; and ignoring her during party meetings.

These experiences were similar to those expressed by women in Gowrie and Sakote. At Gowrie for instance, a female party organiser said:

Hearing that a woman is in politics in a local environment like this, you can guess with certainty, that she simply has the abilities to organise fellow women, and has been drawn in by men to be responsible for women's affairs in a political party to meet their own interests. Few women go beyond this.

Her counterpart at Sakote in the Talensi-Nabdam District maintained a similar view:

Party men only begin to know that there are party women, when it is approaching election time. After that it is only the men whose influence can go beyond the community level, either because they have won elections as MPs or District Chief Executives, or because their affiliated political parties have won the general elections.

A Gender Desk Officer at Bolgatan disclosed that the vulnerability of women to discrimination in the formal sector is not uncommon. While men continue to dominate in managerial and other top positions, the appointment of women of equal qualifications seems to reflect a modification of their reproductive roles in the home. Thus, positions such as Secretary and Receptionist are dominated by women. These administrative injustices against women are influenced by the conceptions that women perform well in jobs that are similar to their roles in home making (Moser, 1993; Tamale, 2004; WILDAF, 2010). It is interesting to observe that most women naturally prefer such jobs for the very reasons expressed above. Thus, in typical Parsonian thinking, the subjugation of females to males in leadership positions is partly due to the juxtaposed 
relationship between patriarchy and modernity (Parsons, 1948), and consistent with Freud's theory of the introjections of normative standards into developing personalities (Peet \& Hartwick, 2009). These conditions lead to the conclusion that the vulnerability of women to inequalities in politics is due to cultural stereotyping, which must be a central point of focus on any issue concerning gender inequalities.

\section{Ideological and Programmatic Bases of Affirmative Action as Effective Tools for Promoting Women's Political Inclusion}

This section presents the views of respondents on the various issues that constitute the ideological and programmatic bases of affirmative action. It marks the starting point of the transition from the psycho-social domains to the transformational strategies and processes in the Social Transformative Framework (Figure 1). The focus is on the exploration of how social-ecology and human capacity contribute to the transformation of imbalances in social systems into equilibriums.

The ideological issues relate to the subjective views on how affirmative action could be an effective tool for dealing with women's vulnerability to political exclusion. On the other hand, the programmatic basis of affirmative action centres on the practical aspects of policy implementation to address the problems of vulnerability to political exclusion by women (Abagre, 2012). These are discussed in the subsection below.

\section{Ideological Position of how Affirmative Action Strategies Could Promote Women Political Inclusion}

Ideologically, the inquiry started with the examination of the opinions of respondents on the necessity of affirmative action as an effective tool for promoting women's political participation in the midst of socio-cultural challenges. According to a respondent from IBIS, affirmative action is necessary because it ensures that gaps within the society are bridged in the shortest possible time. The respondent was referring to evidences of vulnerability such as inequalities in the social, political and economic spheres of life, created by discrimination by gender and other socio-cultural determinants (Mak, 2004; Gauthamadas, 2005).

An official of the Centre for Sustainable Development Initiative (CENSUDI) was of the view that affirmative action is necessary and that:

It helps to compensate for past discrimination, persecution or exploitation by the ruling class of a culture, and to address existing discrimination. In this situation, women have been marginalised for far too long, hence the need to address these imbalances. Affirmative action is therefore expected to 
improve development indicators by reducing inequalities and to facilitate the contribution of particular social groups, particularly women to development.

This reveals the respondent's awareness of the impact of cultural value on women's political subjugation. It is an expression of hope that affirmative action has the power to cause social transformation in such a way that women could meet their expectations in the future. The respondent proceeded to label some components of social ecological framework at the international and national levels. He noted that the United Nations Human/Animal Rights Committee (UNHARC), offers potentials for the attainment of the aspired transformation by women as well as the embodiments of the human capacity and the social ecology components, designated for the common goal (See also Jigyasu, 2004).

An official of Upper East Regional Inter-sectoral Gender Network (UERIGN) said that affirmative action policies lead to conscious efforts aimed at addressing the imbalances between men and women. These are usually related to identified issues of interest, such as participatory decision-making and access to political power. A respondent at the Community Development Advocacy Centre (CDAC) in Bolgatanga, argued that whereas policies such as $40 \%$ of women representation in parliament indicate government support of women's political participation in Ghana, the lack of supporting legal document emphasising the implementation of the policy plays down on the effectuation of women's political rights to parliamentary representation.

The policy of having $40 \%$ of women in parliament is classifiably an aspect of the New Affirmative Action or positive discrimination, because it leads to the promotion of women's political participation but over-riding the process of democratic elections (WILDAF, 2010). According to WILDAF (2010), by 2007 as many as 95 countries of the UN were employing one form of affirmative action policy or the other to increase the representation of women in political decision-making. The average representation of women in politics in such countries in 2007 was about $19.3 \%$ compared to $14.7 \%$ in countries without affirmative action policies. This supports the views of the respondents that affirmative action is relevant as far as women's political interests are concerned.

\section{Programmatic Basis of Affirmative Action for promoting Women's Political Participation through Policy Implementation}

Programmatically, the study investigated institutional roles in the adoption and implementation of some affirmative action policies and strategies for the promotion of women's political participation. In line with this, a Bolgatanga Municipal Assembly respondent said the Assembly is responsible for the implementation of all affirmative 
action policies. These include those formulated and approved by the Parliament of Ghana as well as all international policies ratified by the Government of Ghana. Examples are the National Gender and Children's Policy (1998) and the Millennium Development Goal and Sustainable Development Goal on economic empowerment of women and the promotion of gender equity.

At the Bongo District Assembly, an official revealed that the Assembly is responsible for sensitising local communities on the rights of women. The campaign includes issues of gender equity, training women in leadership skills and empowering them economically to make effective contribution to household economy. The aim is to promote respect for women's ideas at the household decision making level, and gradually transcend to community level politics.

According to a respondent, CENSUDI, among other Education Improvement Projects, targeted at young brilliant but needy girls to access education at all levels. In addition, it belongs to the Northern Network for Education Development (NNED) for the promotion of girl-child education. Another project implemented by CENSUDI is the Equitable Community Based Land Administration Systems (ECOBLAS). This seeks to bring about land acquisition reforms so that women can inherit land like any other member of the family. As of 2011, a pilot project of two communities was running in the Bawku Municipal and Bawku West Districts of the Upper East Region. Women in Participatory Decision Making (WODEM), a more politically oriented affirmative action strategy, is another area of intervention by CENSUDI. This addresses the problem of poor representation of women in decision making at the household, community, district, regional and national levels. CENSUDI, has supported women through capacity building and funding among others, to contest in district level elections.

In response to the issues above, an official of UERIGN, said some affirmative action programmes it initiates and implements include girl child education programmes and programmes for the promotion of women's participation in governance. He pointed out that the two programmes are interrelated because the promotion of girl child education would help address the problem of low women's participation in governance in the future, through the acquisition of educational qualifications that would enable them to compete on equal basis with their male counterparts. UERIGN also supports female candidates in local government elections, as well as the sensitisation of local communities about unearthing leadership potentials in women by supporting and voting for them during elections.

According to an official of IBIS, the organisation plays gender advocacy roles for complete mainstreaming of gender-related issues in the formulation of programmes. He added that the Governance Thematic Framework on Affirmative Action however, assigns and 
supports partners to implement activities aimed at increasing women's participation in politics. This includes: (i) capacity building and mentoring of women participating in district level elections; (ii) facilitating the networking of women in political life at both district and regional levels in the UER, such as Past and Present Assembly Women's Association (PPAWA); (iii) continuous mentoring of women in politics to enable them perform better (accompaniment strategy); and (iv) conducting research into women leadership issues to unearth reasons for the failure of the majority of women to win district level elections.

The discussion under this sub-theme marked the first phase of the execution of the tenet of Transformational Strategies and Processes of the modified Social Transformation Framework by Mak (2004) and Gauthamadas (2005), as applied in this study. That is, how the Human Capacity and Social Ecology components explain the transformation of the situation of vulnerability of women to political marginalisation in the orthodox way has been examined. The nature of the programmes and activities discussed so far appear to be consistent with the set of guidelines for implementing proposals on gender related projects presented to the National Council for Women and Development (NCWD), under the 1998 Cabinet Statement of Policy on Affirmative Action in Ghana, which were as follows:

- To establish a clear cut administrative framework to handle women`s affairs.

- To ensure appropriate representation of women on all advisory bodies

- To mainstream women's issues.

- Initiate action for credible representation of women in parliament.

- To ensure adequate representation of women at district and sub-district levels of administration.

- To make more effective the education and training of women.

- To step up public education on affirmative action. (W ILDAF, 2010).

Most of these provisions have been practiced under the various institutions discussed above. What remain to be covered are the achievements of such interventions in the study area so far.

\section{Effectiveness of the Implemented Programmes for Women's Political Inclusion}

The discussion under this section serves as a means of assessing the actual state of social transformation achieved through affirmative action by various institutions 
through the assessment of their performances. The Bolgatanga Municipal Assembly Gender Desk Officer said that there have been some achievements in the sensitisation of constituencies on the need for gender equity in politics. However, the lack of funds for the implementation of programmes by the Assembly affects the level of successes. He added that the Assembly is mandated to make available to private sector and civil society organisations the national and international policies as well as other development priorities by sectors approved by the Government of Ghana. Such partners are therefore expected to operate within the available policy frameworks.

Responding to the same question on the effectiveness of implemented affirmative action policies, an official of CENSUDI said: that although their organisation is relatively young, it has chalked remarkable successes, including the following:

- Increase in the proportion of female candidates by $30 \%$ in 1996 over that of 1992, and 40\% in 1998 over that of 1994 in National level elections;

- Three female candidates won seats in the 1996 district elections as a result of training received from CENSUDI;

- Increased ability of female candidates to gain media coverage resulting from training received from CENSUDI on media and leadership strategies;

- Appointment of one woman as Minister of State, two as Deputy Ministers, and one to head a very influential NGO;

- Lobbied for political parties to revise portions of their manifestos on issues of gender equity;

- Fifty women and men from 18 women and gender focused NGOs in the three northern regions educated by CENSUDI on gender and public life skills and organisational development and management. All of the NGOs are now solidly on the ground and doing very well. Even about $30 \%$ of them are now doing better than CENSUDI, especially in areas of resource mobilisation, programme development and outreach to poor rural women;

On the part of IBIS (Bolgatanga), it was reported that the programmes and activities have not fared badly. The respondent acknowledged:

Our advocacy and lobbying efforts to encourage more appointment of women in leadership at District Assembly levels have yielded minimal results. More innovative strategies and approaches remain unexploited to enable us succeed in this regard, as a result of imbalances in institutional networking.

UERIGN, revealed that its implemented programmes have largely been successful, giving women the confidence to participate in governance. However, the deep-rooted cultural practices in the region remain a serious challenge for women's participation in politics. 
This view confirms the contention that the conditions of women are still unfriendly at both job place and social level environments due to gender stereotyping and patriarchal structures (UNDSEA, 2000).

At the community level a former female politician in Yekene associated some positive changes in the relationships between men and women in some aspects of decision making and power sharing with the activities of some NGOs. She cited the Equitable Community Based Land Administration Systems and Women in Participatory Decision Making being implemented by CENSUDI as examples. On the same question, a former Assembly Woman at the Gowrie community said:

Through the affirmative action programmes by organisations like the $31^{\text {st }}$ December Women's Movement, many of us have learnt to perform our responsibilities when we occupy political and other formal sector leadership positions as women. It was through such programmes that I gained the courage to participate in politics and won the position of Assembly Woman by elections, not by appointment.

Despite the above achievements, gender disparities in political participation is still a problem. Table 1 presents the representations of District Assembly men and women in the Upper East Region as of 2015. It shows that the composition of women in the District Assemblies is close to only 10 percent compared to male representation. The population structure of the Upper East Region, provides enough grounds to question such a wide disparity between men and women at the Assembly level elections. According to Ghana Statistical Service (2013), females make up 51.6 percent of the population of the Region, compared to males (48.4 percent).

In terms of age, 53.5 percent of females are in the age group 15-64, compared to 49.7 percent of males, meaning that females have more potentials than males, given the legal age of 18 years for political participation in Ghana. Despite the numerous efforts to solve the problem of gender inequality in politics, the situation exposed in Table 1, generates further interest in the socio-cultural causalities. Peet and Hartwick (2009), describe the potential of cultural instincts to create stable patterns of social interactions controlled by norms through socialisation, which inculcates belief systems and norms into generations, making it possible for both males and females to assimilate the positions assigned to them by culture. In such a society, even where females could significantly impact election results by their numbers, they would prefer males to fellow female candidates (Gukari, 2008). 
Table 1: Election of district assembly representatives by gender - 2015

\begin{tabular}{|l|l|l|l|l|l|l|l|}
\hline \multirow{2}{*}{ District } & \multicolumn{2}{l}{ Female } & \multicolumn{2}{l}{ Male } & \multicolumn{3}{l}{ Grand } \\
\cline { 2 - 9 } & Elected & Appointed & Total & Elected & Appointed & Total & \\
\hline Builsa South & 1 & 1 & 2 & 19 & 8 & 27 & 29 \\
\hline Builsa North & - & 3 & 3 & 31 & 11 & 42 & 45 \\
\hline $\begin{array}{l}\text { Kassena/Nankana } \\
\text { Mun. }\end{array}$ & 1 & 3 & 4 & 33 & 12 & 45 & 49 \\
\hline $\begin{array}{l}\text { Kassena/Nankana } \\
\text { West }\end{array}$ & 2 & 3 & 5 & 44 & 17 & 61 & 66 \\
\hline Bolgatanga & 1 & 5 & 6 & 36 & 11 & 47 & 53 \\
\hline Bongo & 1 & 8 & 9 & 37 & 8 & 45 & 54 \\
\hline Talensi & 1 & 2 & 3 & 21 & 8 & 29 & 32 \\
\hline Nabdam & - & 2 & 2 & 13 & 4 & 17 & 19 \\
\hline Bawku West & - & 4 & 4 & 34 & 11 & 45 & 49 \\
\hline Bawku municipal & - & 3 & 3 & 20 & 6 & 26 & 29 \\
\hline Pusiga & - & 2 & 2 & 15 & 4 & 19 & 21 \\
\hline Garu-Tempane & 1 & 4 & 5 & 29 & 9 & 38 & 43 \\
\hline Binduri & 1 & 1 & 2 & 11 & 4 & 15 & 17 \\
\hline Total & $\mathbf{9}$ & $\mathbf{4 1}$ & $\mathbf{5 0}$ & $\mathbf{3 4 3}$ & $\mathbf{1 1 3}$ & $\mathbf{4 5 6}$ & $\mathbf{5 0 6}$ \\
\hline $\begin{array}{l}\text { Percentage of } \\
\text { women represented }\end{array}$ & & & & & & & $9.90 \%$ \\
\hline $\begin{array}{l}\text { Percentage of men } \\
\text { represented }\end{array}$ & & & & & & & $90.10 \%$ \\
\hline Source & & & & & & \\
\hline
\end{tabular}

Source: Electoral Commission of Ghana (2015).

Theoretically, the conceptualised framework for this study also provides a mechanism for review of any identified shortfalls in the social transformation process. The framework identifies the importance of social research in diagnosing persisting challenges and making proposals for redress. This implies the enhanced adoption of human capacity to manipulate the cultural and social ecology components to achieve a refined social transformation. This is consistent with Durkheim's idea of collective conscience, which deals with a system of adopted common values to secure a preferred social order (Durkheim, 1983), or Marx Weber's notion of rational action, which anchors on the importance of ideas and values as driving forces of social change (Weber, 1978). 


\section{Conclusions and Recommendations}

It was established that the vulnerability context of the study emanates from sociocultural factors, especially patriarchy and how it impinges on women's political participation. These are manifested at the household level in the forms of exclusion from being family heads, decision-making and inheritance of family property. At the community level, the socialisation of women as home keepers inhibits against their participation in community decision-making and leadership roles. The same story applies to national level politics; the socio-cultural factors make both men and women perceive participation in national level politics as being male dominant. These conditions along with the awareness of the existence and implementation of affirmative action policies, as well as evidences of the active roles of the Local Government and Civil Society Organisations, complete the cultural values, social-ecology and human capacity components of the psycho-social tenet of the social transformation framework.

Despite the institutional involvement in the ideological and programmatic bases of affirmative processes for the promotion of women's political participation, they are not without limitations. The national level institutions such as the Ministry of Gender, Children and Social Protection, as well as the Parliament of Ghana have not been seen to play active roles in the fight against the effects of socio-cultural factors on women's political participation. The lack of the active roles of such institutions to ensure the political will and involvement at the various stages of the transformative process, reduce the affirmative action policies and strategies close to nothing but toothless bull dogs. This is because the present level of women's participation in politics is still far from being equal to that of men.

For effective cultural change for women's political emancipation, it is recommended that there should be enhanced sensitisation of women about their political rights. This should be backed by the promotion of girls' education and adult education programmes for women, especially in the rural areas where such socio-cultural instincts are high. Public education programmes through the National Commission for Civic Education and the national media could also play active roles in debasing the effects of negative perceptions such as women being incompetent as leaders from the minds of the citizens.

Since the challenge of women's marginalisation is culturally influenced, traditional leaders as the custodians of culture should be involved in the situational analysis and project design to address the menace in the respective cultural areas. These, in addition to the encouragement of successful women in politics to act as role models to inspire young women in their respective constituencies, could reduce the negative effects of culture on women's political participation. 


\section{References}

Abagre, C.I. (2012). Affirmative action as a strategy for women's political inclusion in Ghana: An examination of socio-cultural factors impinging on the use of affirmative action in the Upper East Region. A master thesis. Tamale: University for Development Studies.

African Union (AU) (2012). Social transformation: policy document for African Nations Charter. Addis Ababa: AU.

Akpah, P. (2013). List of 29 women in parliament. Modern Ghana Online Radio Centre, 21/01/2013. Accessed 02/05/2016. s://wwhttpw.modernghana.com/ news/440537/1/list-of-the-29-women-in- parliament.html.

Apusigah, A. A. (2004). Gender, vulnerability and the politics of decision-making in Ghana: the case of the Upper East Region. Ghana Journal of Development Studies, Vol. 1, No. 2, pp. 6-26.

Baden, S., Green, C., Otoo-Oyortey, N., and Peasegood, T. (1994). Background paper on gender issues in Ghana. Brighton: BRIDGE - development gender. Report No. 19 (i-xi).

Ballington, J.W. (2004). Implementation of quotas: African experiences. Stockholm: The International Institute of Electoral Assistance. Quota report series No. 3 (11-122)

Bari, F. (2005). Women's political participation: issues and challenges. Bangkok: Division for the Advancement of Women.

Bekye, P.K. (1998). Peasant development: the case of Northern Ghana. Acco: Leuven.

Branner, R. (2007). Auditing \& statistical sampling: Current and best practices. Michigan State: Michigan Department of Treasury.

Bukari, F.I.M. (2009). Traditional gender notions and their influence on women access to political office: an analysis of the perceptions of choice of party candidates in Bole in the Northern Region of Ghana. Gender Works: An occasional paper on gender in development praxis, Vol.2, pp. 90-100.

Bukari, F.I.M. and Abagre, C.I. (2013). An alternative model for pro-poor water services: Improving water tariff payments in low income communities. Journal of Environmentand Earth Science, Vol. 3 No.8 pp. 157-165.

Department for International Development (DFID) (2008). Sustainable livelihoods guidance sheet: vulnerability context. London: DFID.

Durkheim, E. (ed.). (1983). The division of labour in society. New York: Free Press. 
Electoral Commission of Ghana (2015). Female representation in district assemblies in Upper East Region-2015 district level elections. Accessed January 15, 2016. http://www. ec.gov.gh/elected-members-for-the-district-level-election- 2015.

Folke, C. (2006). Resilience: the emergence of a perspective for social-ecological systems analyses. Global Environmental Change, Vol. 16, pp. 253-267.

Gauthamadas, U. (2004).Psychosocial engineering as a means of re-establishing lives in theTsunami affected community. Presentation at the Asia Pacific Congress on disaster mitigation, April 2005.

Getis, A., Getis J. and Fellman, J.D (2006).Introduction to geography. New York: McGrawHill.

Ghana News (2013). Number of women MPs in parliament affects gender issues. Ghana News, 12/11/2013. Accessed 02/05/2013. http://www.newsghana.com.gh/numberof-women-mps-in-parliament-affects-gender-issues.

Ghana Statistical Service (GSS) (2013). 2010 Population and Housing Census, regional analytical report: Upper East Region. Accra: GSS.

Jigyasu, R. (2004). Sustainable post disaster reconstruction through integrated risk management: the case of rural communities in South Asia.Wisconsin: University of Wisconsin.

Kane, E. (1995). Seeing for yourself: Research handbook for girls in Africa.Washington D.C: The International Bank for Reconstruction andDevelopment/ The World Bank.

Kaufman, P. (2003). Learning to not labour: how working-class individuals construct middle class identities. Sociological quarterly, Vol. 44, No. 3, pp. 481-504.

Kubilay, A. (2008). Ambiguities of social transformation: a critical framework for the concept. Journal of US-China Public Administration. 5 (6): 23-27.

Mak, S. (2004).Poverty, vulnerability and livelihood in Cambodia. Presentation From Sumernet Partners Meeting 2004.

Meena, R. (2004). The politics of quotas in Tanzania. In Bellington, J, (ed.). The implementation of Quotas African Experiences. Quota report series, No.3, p.82-87.

Moser, C.O.N. (1993). Gender planning and development: Theory, practice and training. London: Routledge.

Odame, F.S. (2010). Women in politics in Ghana: A study on local government in the Greater Accra Region. Ghana Journal of Developmet Studies, Vol. 7, No. 1, pp.73-95.

Parsons, T. (1948). The structure of social action. New York: McGraw-Hill. 
Peet, R. and Hartwick, E. (2009). Theories of development: Contentions, arguments, Alternatives ( $2^{\text {nd }}$ ed.). New York: The Guilford Press.

Regional Parliamentary Assemblies (2015). Women in national parliaments. Geneva: Inter Parliamentary Union.

Scoones, I. (1998). Sustainable rural livelihoods: a framework for analysis. Working Paper 72. Brighton: Institute for Development Studies.

Stone, W.H. and Gregory, P. (1957). Urbanism, anonymity, and status symbolism. American Journal of Sociology, Vol. 62, No. 5, pp. 504-514.

Tamale, S. (2004).VIntroducing quotas: discourse as legal reforms in Uganda. In Ballington, J. (ed). The implementation of quotas: African experiences. Stockholding: International Institute of Democracy and Electoral Assistance Quota Report Series No. $3(38-45)$.

True, T., George, N. Niner, S. and Parashar, S. (2014). Women's political participation in Asia and the Pacific. Conflict prevention and peace forum, CPPF working papers on women in politics: NO. 3 .

Tsikata, D. (2009). Affirmative action and the prospects for gender equality in Ghanaian politics. Accra: Wib and Friedrich Ebert Stifting.

Weber, M. (1978). Max Weber: selections in translation. In Runciman, W. G. (Ed.). Cambridge: Cambridge University Press.

WILDAF (2010). .Analysis of affirmative action policy for women's participation in politics and decision making in Ghana. Accra, Ghana: WILDAF.

Zuul, B.S. (2011). Jesus Christ of Frafraland: a study of the interface of the gospel and theFrafra culture and its implications for evangelisation in the Frafra context. A master thesis. Kumasi: Kwame Nkrumah University of Science and Technology. 